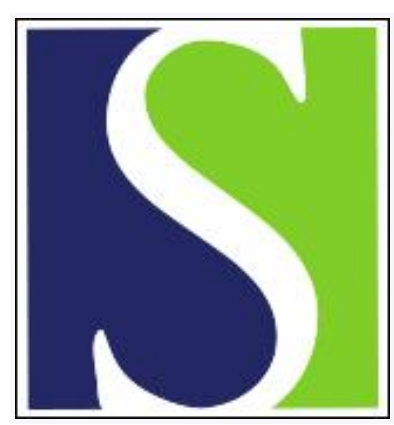

Scand J Work Environ Health 1999;25(5):430-435

https://doi.org/10.5271/sjweh.456

Issue date: Oct 1999

\title{
Adult-onset asthma and occupational exposures
}

by Torén K, Järvholm B, Brisman J, Hagberg S, Hermansson B-A, Lillienberg $\mathrm{L}$

The following article refers to this text: 2022;48(1):1-3

Key terms: asthma; epidemiology; questionnaire; retrospective study

This article in PubMed: www.ncbi.nlm.nih.gov/pubmed/10569463

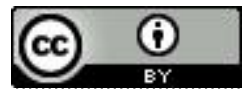




\title{
Adult-onset asthma and occupational exposures
}

\author{
by Kjell Torén, MD, ,,2 Bengt Järvholm, MD, ${ }^{3}$ Jonas Brisman, MD, ${ }^{1,2}$ Stig Hagberg, MSc, ${ }^{1}$ Bengt-Arne \\ Hermansson, $M D,{ }^{4}$ Linnea Lillienberg, $P h D^{1}$
} Torén K, Järvholm B, Brisman J, Hagberg S, Hermansson B-A, Lillienberg L. Adult-onset asthma and occupation-
al exposures. Scand J Work Environ Health 1999;25(5):430-435.

\begin{abstract}
Objectives This study examined certain occupational exposures and the risk for adult-onset asthma. Methods A nested case-referent study of adult-onset asthma was performed on a random population sample $(\mathrm{N}=15$ 813), aged 21 to 51 years. Cases for the study included 2 groups: subjects reporting "physician-diagnosed" asthma ( $\mathrm{N}=251)$ and a broader "asthma" group $(\mathrm{N}=362)$. The "asthma" group consisted of subjects with "physician-diagnosed" asthma ( $N=251)$ and subjects reporting asthma-like symptoms without having "physician-diagnosed" asthma $(\mathrm{N}=111)$. The referents $(\mathrm{N}=2044)$ were randomly selected from the whole population sample. The case-referent sample was investigated with a comprehensive questionnaire about occupational exposures, asthma, respiratory symptoms, smoking, and atopy. Odds ratios were calculated with stratification for gender, year of diagnosis, and birth year.

Results The highest odds ratio for "physician-diagnosed" asthma was associated with exposure to flour dust [odds ratio (OR) $2.8,95 \%$ confidence interval $(95 \% \mathrm{CI}$ ) 1.5-5.2] and the occupational handling of resin-based paints (isocyanates) (OR 3.0, 95\% CI 1.6-5.9). Exposure to welding fumes, textile dust, and work with glues containing acrylates was also associated with an increased odds ratio for "physician-diagnosed" asthma. Including persons with asthma-like symptoms (ie, the asthma group) showed similar results.
\end{abstract}

Conclusion This population-based case-referent study from Sweden indicates that occupational exposure to acrylate-based compounds and welding fumes is associated with increased risk for adult-onset asthma.

Key terms asthma, epidemiologic, occupational, questionnaires, retrospective.

Many occupational exposures can cause asthma. Exposure to reactive synthetic chemicals, such as isocyanates, or biological agents is associated with risk for occupational asthma. Our knowledge about such risk in the general population is, however, limited. Most studies are case reports, register-based case series, or investigations of certain occupational cohorts with predefined exposure. The design of choice in investigating the population risk is a population-based study. We are aware of a few such studies $(1-4)$, one of which was designed as a retrospective case-referent study (1). Besides, we have found 2 hospital-based case-referent studies $(5,6)$ and 2 case-referent studies among members in health maintenance organizations in the United States $(7,8)$.

One major problem in population-based studies is the assessment of exposure. Many types of exposures are scattered across different occupations, and job titles are poor indicators of occupational exposure. A more sensitive method is to ask the subjects whether they have been exposed to particular substances and then use their responses as the variables for analysis (9).

Using a short respiratory questionnaire (10), we investigated a random population sample $(\mathrm{N}=15813)$ aged 20 to 50 years. The subjects were asked whether they had "physician-diagnosed" asthma and whether they had asthma-like symptoms, that is, attacks of wheezing and breathlessness with symptom-free intervals in between. In this paper, we analyzed risks for asthma and asthmalike symptoms in relation to certain occupational exposures using a nested case-referent study.

\section{Subjects and methods}

The study was based on a cross-sectional population sample. Briefly, 20000 subjects aged 20 to 50 years were

1 Department of Occupational and Environmental Medicine, Sahlgrenska University Hospital, Göteborg, Sweden.

2 Department of Respiratory Medicine and Allergology, Sahlgrenska University Hospital, Göteborg, Sweden.

3 Department of Occupational and Environmental Medicine, Umeå University, Umeå, Sweden.

4 Department of Chest Medicine, Borås Hospital, Borås, Sweden.

Reprint requests to: Dr Kjell Torén, Sahlgrenska University Hospital, Section of Occupational and Environmental Medicine, St Sigfridsgatan 85b, S-412 66 Göteborg, Sweden. [E-mail: Kjell.Toren@ymk.gu.se] 
asked to complete a short respiratory questionnaire, and, after 2 reminders, it was answered by 15813 subjects (10). The study was performed in the most industrialized county in Sweden, with a predominance of traditional industry, such as textile industries, pulp and paper mills, saw mills, car manufacturing and smelteries.

In the questionnaire, the subjects were asked "Have you been diagnosed by a physician as having asthma?", followed by the question, "If 'Yes', how old were you then?" (11). The subjects were also asked about asthmalike symptoms: "Have you ever had attacks of wheezing of the chest?" and "Have you - at any time - suffered from attacks of shortness of breath?" Both of these questions were followed by "If 'Yes', how old were you when you noticed it for the first time?" These questions were followed by: "If 'Yes' to these 2 questions, is your breathing normal between attacks?" A subject was regarded as having asthma-like symptoms if he responded "yes" to these 3 questions about wheezing, shortness of breath, and normal breathing between attacks.

In the second phase of the study, 1 year later, we performed a nested case-referent study. Subjects with "physician-diagnosed" asthma from 16 years of age $(\mathrm{N}=374)$ on were used as cases, along with subjects with asthmalike symptoms first noticed from 16 years of age without reporting "physician-diagnosed" asthma ( $\mathrm{N}=148$ ). The referents $(N=2400)$ consisted of a random subsample from the original large population sample. All the subjects $(\mathrm{N}=2922)$ were then asked to complete a comprehensive postal questionnaire with detailed questions about their occupations and certain occupational exposures, as well as some of the questions from the screening questionnaire about "physician-diagnosed" asthma and asthma-like symptoms, cough with phlegm, and smoking habits. After 4 reminders, the questionnaire was answered by 440 cases ( $84 \%$ ) and 2044 referents $(85 \%)$. All the questionnaires were checked upon arrival, and, when incomplete answers were given, the respondents were phoned and asked to give complete answers.

Hence, the subjects were asked twice, both in the screening questionnaire and in the current case-referent questionnaire, if they had "physician-diagnosed" asthma or asthma-like symptoms. In the subsequent analyses, we used 2 running definitions of asthma as follows:

1. "Physician-diagnosed" asthma was defined as a positive response to the question about "physician-diagnosed" asthma in both the screening and the case-referent questionnaire, combined with a report of a year of diagnosis after 15 years of age.

2. Asthma was defined as a positive answer to both items about wheezing and shortness of breath, combined with a statement of normal breathing between attacks (asthma-like symptoms) and a reported starting date for the symptoms after 15 years of age or a positive response to "physician-diagnosed" asthma. Also in this group, a positive response to both the screening and the case-referent questionnaire was required.

In accordance with these definitions, the study included 362 cases with asthma, 251 of which were defined as "physician-diagnosed" asthma. The selection of the cases and referents is shown in figure 1.

Atopy was defined as a positive response to the question "Did you suffer from any kind of allergy when you were a child, for instance, atopic dermatitis, asthma or allergic rhinitis?"

The occupational exposure classification of the subjects was based on their self-reports. The questions about occupational exposures were worded as follows: "In your work, have you been exposed to . . . ?" "If 'yes', between which years . . ?"' Such, questions were asked about 28 types of occupational exposures (table 1).

The types of exposures asked about were selected for a variety of reasons. First, we tested the a priori hypothesis that there is an increased risk for adult-onset

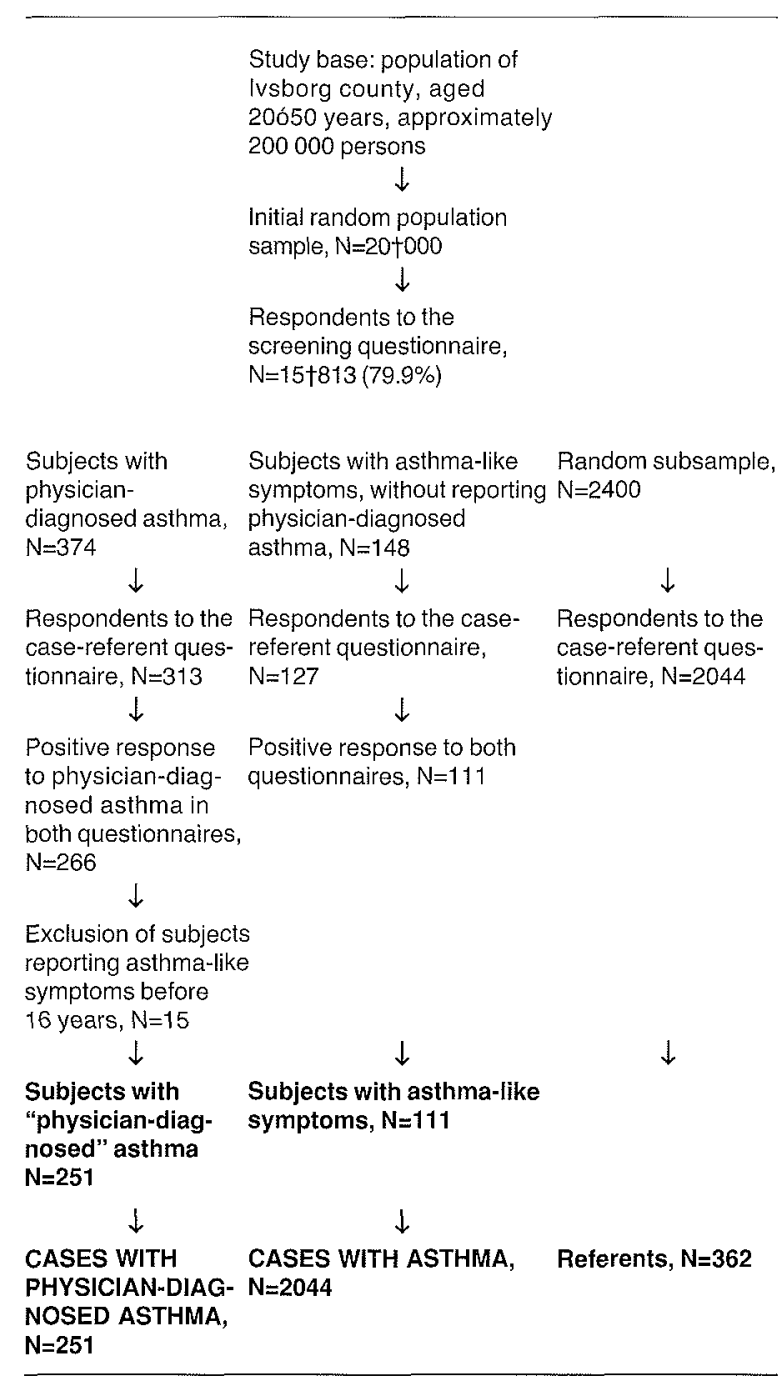

Figure 1. Flow chart showing the selection of cases and referents for the study. 
asthma after exposure to certain low-molecular-weight agents by asking about exposure to rapid glues, welding fumes, and paint hardeners (isocyanates). Second, we tested the hypothesis that exposure to dust, both organic and inorganic, fumes, and irritants may increase the risk for asthma. Third, we asked about flour dust, a wellknown occupational sensitizer, as a "positive control".

Table 1. Wording of questions regarding self-assessed occupational exposures. All the questions were followed by 'If 'yes', between which years?" The prevalence of positive answers among the controls $(N=2044)$ is given.

\begin{tabular}{|c|c|c|}
\hline \multirow[t]{2}{*}{ Wording } & \multicolumn{2}{|c|}{ Prevalence (\%) } \\
\hline & Men & Women \\
\hline \multicolumn{3}{|l|}{ Have you been exposed to } \\
\hline welding fumes? & 33.9 & 2.3 \\
\hline mineral dust? & 18.2 & 1.0 \\
\hline man-made mineral fibers? & 19.9 & 1.2 \\
\hline asbestos? & 18.8 & 0.8 \\
\hline grain dust? & 8.4 & 3.5 \\
\hline flour dust? & 6.4 & 3.9 \\
\hline wood dust? & 20.5 & 2.6 \\
\hline paper dust? & 10.8 & 11.1 \\
\hline textlle dust? & 11.4 & 18.3 \\
\hline cotton dust? & 2.2 & 1.0 \\
\hline sulfur dioxide? & 3.8 & 0.6 \\
\hline chlorine? & 3.1 & 0.7 \\
\hline strong acids? & 10.8 & 3.5 \\
\hline formaldehyde? & 6.8 & 4.3 \\
\hline fire fumes? & 6.0 & 0.8 \\
\hline engine exhausts? & 24.8 & 4.7 \\
\hline \multicolumn{3}{|l|}{ Have you worked with } \\
\hline soldering? & 18.5 & 2.2 \\
\hline tanning? & 1.7 & 0.5 \\
\hline rubber chemicals? & 5.3 & 0.9 \\
\hline grinding? & 28.9 & 2.5 \\
\hline reactive dyes? & 2.0 & 0.3 \\
\hline rapid glues (Loctiteß) & & \\
\hline cyanoacrylates or Omnifit(B))? & 2.0 & 0.3 \\
\hline paint hardeners/isocyanates? & 16.0 & 2.4 \\
\hline polyuretan foam? & 6.8 & 0.2 \\
\hline cutting oils/fluids? & 15.7 & 0.8 \\
\hline \multicolumn{3}{|l|}{ Have you worked as a } \\
\hline cleaner? & 6.1 & 23.3 \\
\hline textile dyer? & 1.8 & 0.3 \\
\hline hairdresser? & - & 1.5 \\
\hline
\end{tabular}

Table 2. Description of the study population. The cases were the subjects with asthma (ie, the combined group of subjects with physician-diagnosed asthma and subjects with asthma-like symptoms without "physician-diagnosed" asthma). Atopy was defined as a positive response to the question "Did you suffer from any kind of allergy when you were a child, for instance, atopic dermatitis, asthma or allergic rhinitis?"

\begin{tabular}{lccccc}
\hline & \multicolumn{2}{c}{ Men } & & \multicolumn{2}{c}{ Women } \\
\cline { 2 - 3 } \cline { 5 - 6 } & $\begin{array}{c}\text { Cases } \\
N=151\end{array}$ & $\begin{array}{c}\text { Referents } \\
N=991\end{array}$ & & $\begin{array}{c}\text { Cases } \\
N=211\end{array}$ & $\begin{array}{c}\text { Referents } \\
N=1053\end{array}$ \\
\cline { 6 - 6 } Age (years) & 39.9 & 37.0 & 40.0 & 36.8 \\
Never smokers (\%) & 37.8 & 52.0 & & 34.6 & 48.3 \\
Ex-smokers (\%) & 39.0 & 27.6 & 33.6 & 24.8 \\
Current smokers (\%) & 23.2 & 20.4 & 31.8 & 20.6 \\
Atopy (\%) & 34.4 & 16.7 & 31.8 & 20.6 \\
\hline
\end{tabular}

There were more smokers and atopics among the cases than among the referents. A more-detailed description of the study population is presented in table 2 .

\section{Statistical analyses}

The cases and referents were divided into the following 3 classes according to their birth year: 1943-1952, 1953-1962, 1963-1972. The cases were diagnosed in the years 1958 to 1993 , and they were further divided into 3 classes according to their year of diagnosis as follows: $1958-1970(5 \%), 1971-1982(16 \%)$, and 1983$1993(79 \%)$. The percentage diagnosed in each interval is shown in parentheses.

As we were interested only in the exposures before the onset of asthma, taken as the year of diagnosis, we also had to define an anchor point in time for each referent. Therefore, in each birth-year class, the referents were randomly allocated into a diagnosis-year class. The number of referents allocated into each diagnosis-year class was weighted by the number of actual cases. Each referent was then assigned the midyear in its diagnosisyear class as its anchor year.

To be classified as exposed, the subjects had to report exposure the year of diagnosis or the previous year. As the subjects answered questions about 28 different types of exposures, many subjects reported more than 1 type of exposure during the crucial 2 years associated with the asthma diagnosis.

Table 3. Odds ratio (OR) for asthma and "physician-diagnosed" asthma according to occupational exposure. The odds ratios have been determined according to Mantel-Haenszel, stratified for gender, year of diagnosis, and birth-year. The exposure categories are not mutually exclusive. ( $95 \% \mathrm{Cl}=$ confidence interval, $\mathrm{N}=$ number of exposed cases)

\begin{tabular}{|c|c|c|c|c|c|c|}
\hline \multirow[t]{2}{*}{ Exposure } & \multicolumn{3}{|c|}{ Asthma } & \multicolumn{3}{|c|}{$\begin{array}{l}\text { Physician- } \\
\text { diagnosed } \\
\text { asthma }\end{array}$} \\
\hline & $N$ & OR & $95 \% \mathrm{Cl}$ & $\mathbb{N}$ & $\mathrm{OR}$ & $95 \% \mathrm{Cl}$ \\
\hline Welding fumes & 39 & 1.5 & $1.0-2.3$ & 28 & 1.6 & $1.1-2.6$ \\
\hline Soldering & 13 & 0.9 & $0.5-1.7$ & 10 & 1.0 & $0.5-2.0$ \\
\hline Grinding & 31 & 1.4 & $0.9-2.1$ & 21 & 1.4 & $0.9-2.4$ \\
\hline Mineral dust & 23 & 1.6 & $1.0-2.6$ & 11 & 1.1 & $0.6-2.1$ \\
\hline Man-made mineral fibers & 10 & 0.6 & $0.3-1.2$ & 6 & 0.6 & $0.2-1.3$ \\
\hline Asbestos & 17 & 1.5 & $0.8-2.6$ & 10 & 1.4 & $0.7--2.8$ \\
\hline Grain dust & 12 & 1.3 & $0.7-2.5$ & 10 & 1.7 & $0.8-3.3$ \\
\hline Flour dust & 15 & 2.2 & $1.2-3.9$ & 13 & 2.8 & $1.5--5.2$ \\
\hline Wood dust & 17 & 1.0 & $0.6-1.7$ & 11 & 0.9 & $0.5-1.8$ \\
\hline Paper dust & 31 & 1.5 & $1.0-2.3$ & 20 & 1.4 & $0.8-2.3$ \\
\hline Textile dust & 36 & 1.5 & $1.0-2.3$ & 25 & 1.5 & $0.9-2.4$ \\
\hline Strong acids & 10 & 1.2 & $0.6-2.4$ & 8 & 1.4 & $0.6-2.9$ \\
\hline Formaldehyde & 11 & 1.0 & $0.5-2.0$ & 8 & 1.1 & $0.5-2.3$ \\
\hline Fire fumes & 6 & 1.6 & $0.6-3.9$ & 5 & 2.0 & $0.8-5.4$ \\
\hline Engine exhaust & 33 & 1.4 & $0.9-2.0$ & 17 & 1.0 & $0.6-1.7$ \\
\hline Rapid glues (Loctite $(\mathbb{B})$ & 21 & 1.7 & $1.1--2.9$ & 15 & 1.8 & $1.0-3.2$ \\
\hline Paint hardeners (isocyanates) & 14 & 2.3 & $1.2-4.3$ & 12 & 3.0 & $1.6-5.9$ \\
\hline Polyurethane foam & 5 & 1.5 & $0.5-4.0$ & 5 & 2.1 & $0.8-5.4$ \\
\hline Cutting fluids & 13 & 1.1 & $0.6-2.1$ & 9 & 1.2 & $0.6-2.5$ \\
\hline Work as a cleaner & 23 & 1.3 & $0.8-2.1$ & 18 & 1.4 & $0.8-2.4$ \\
\hline Ammonia & 14 & 1.2 & $0.6-2.1$ & 9 & 1.0 & $0.5-2.3$ \\
\hline
\end{tabular}


The material was stratified for gender, age class, and birth-year class, and odds ratios (OR) were calculated according to Mantel-Haenszel. Only exposure categories with 5 or more exposed cases were considered in the final analysis. If the number of exposed cases exceeded 20 , stratification for smoking habits (never smoker; ever smoker) and atopy was added. In addition, among occupations or exposures with more than 20 exposed cases, the odds ratio for the subjects who were exposed for more than 5 years was analyzed. Confidence intervals $(95 \%)$ were calculated with the test-based method (12).

Logistic regression analysis was used to adjust for exposure interaction. For the analyses the Statistical Analysis System (SAS) statistical package (version 6.11) was used, and odds ratios with $95 \%$ confidence intervals $(95 \%$ CI) were estimated (11). In the analyses, combined groups of exposures were introduced in the regression models, adjusted for gender, smoking (never smoker;ever smoker), and atopy.

\section{Results}

The odds ratios for the exposure categories, with genders merged, for asthma and physician-diagnosed asthma are shown in table 3 . With stratification for atopy and smoking, the odds ratios for asthma changed only marginally, as compared with the odds ratios after stratification for gender, year of diagnosis, and birth year (table 4).

Table 5 shows the odds ratios for asthma among the men and women separately. For the men, increased odds ratios were associated with work with rapid glues (Loctite ${ }^{\circledR}$, Omnifit ${ }^{\circledR}$, cyanoacrylates) and resin-based paints. For the women, increased odds ratios were associated with exposure to textile dust, flour dust, and engine exhaust.

The odds ratios for asthma did not differ when the analyses were restricted to exposures with a duration of 5 years or more. The odds ratio for asthma and welding fume was 1.8 (95\% CI 1.1-2.8), for asthma and paper dust exposure it was 1.4 (95\% CI 0.8-2.3), and for asthma and rapid glues it was 1.9 (95\% CI 0.9-3.8).

In the logistic regression models controlling for gender, smoking, and atopy (table 6) increased odds ratios for "physician-diagnosed" asthma was associated with exposure to welding fumes (OR $1.8,95 \%$ CI 1.0-3.2), flour dust (OR 2.8, 95\% CI 1.1-6.9), textile dust (OR $1.5,95 \% \mathrm{CI} 1.0-2.3)$, and work with resin-based paints (OR 2.9, 95\% CI 1.4-6.1).

In the questionnaires, information was requested about occupational career. The occupational titles in the year of asthma onset for the 21 asthma cases reporting work with rapid glues were machinery fitter $(\mathrm{N}=6)$, construction worker $(\mathrm{N}=3)$, welder $(\mathrm{N}=2)$, metal worker
Table 4. Odds ratio (OR) for asthma according to occupational exposure. The odds ratios have been determined according to Mantel-Haenszel, stratified for gender, atopy, smoking, year of diagnosis, and birth. Only exposures with more than 20 exposed cases have been considered. $(95 \% \mathrm{Cl}=95 \%$ confidence interval)

\begin{tabular}{lcc}
\hline Exposure & OR & $95 \% \mathrm{Cl}$ \\
\hline Welding fumes & 1.5 & $1.0-2.2$ \\
Mineral dust & 1.5 & $0.9-2.4$ \\
Grinding & 1.6 & $1.0-2.4$ \\
Paper dust & 1.5 & $0.9-2.3$ \\
Textile dust & 1.6 & $1.1-2.3$ \\
Engine exhaust & 1.3 & $0.9-2.0$ \\
Rapid glues (Loctite@) & 1.8 & $1.1-3.0$ \\
Work as a cleaner & 1.2 & $0.8-2.1$ \\
\hline
\end{tabular}

Table 5. Odds ratio $(O R)$ for asthma among the men and women according to occupational exposure. The odds ratios (MantelHaenszel) have been stratified for year of diagnosis and birth year. Only exposures with 5 exposed cases or more for each gender have been considered in the analyses. $(95 \% \mathrm{Cl}=95 \%$ confidence interval)

\begin{tabular}{|c|c|c|c|c|}
\hline \multirow[t]{2}{*}{ Exposure or occupation } & \multicolumn{2}{|c|}{ Men } & \multicolumn{2}{|c|}{ Women } \\
\hline & $\mathrm{OR}$ & $95 \% \mathrm{Cl}$ & OR & $95 \% \mathrm{Cl}$ \\
\hline Welding fumes & 1.4 & $0.9-2.2$ & - & . \\
\hline Soldering & 0.7 & $0.4-1.5$ & - & . \\
\hline Grinding & 1.5 & $0.9-2.3$ & - & . \\
\hline Cutting fluids & 1.2 & $0.6-2.2$ & - & . \\
\hline Mineral dust & 1.3 & $0.8-2.3$ & - & \\
\hline Man-made mineral fibers & 0.6 & $0.3-1.2$ & - & . \\
\hline Asbestos & 1.5 & $0.8-2.7$ & - & . \\
\hline Grain dust & 1.1 & $0.5-2.5$ & - & \\
\hline Flour dust & 1.9 & $0.9-4.3$ & 2.5 & $1.0-5.9$ \\
\hline Wood dust & 0.9 & $0.5-1.7$ & - & \\
\hline Paper dust & 1.4 & $0.7-2.8$ & 1.6 & $0.9-2.7$ \\
\hline Textile dust & 1.0 & $0.5-2.3$ & 1.8 & $1.1-2.8$ \\
\hline Strong acids & 0.9 & $0.4-2.3$ & - & \\
\hline Ammonia & 0.8 & $0.4-2.0$ & 1.7 & $0.8-3.9$ \\
\hline Formaldehyde & 0.9 & $0.4-2.5$ & 1.1 & $0.5-2.7$ \\
\hline Fire fume & 1.3 & $0.5-3.5$ & - & \\
\hline Engine exhaust & 1.1 & $0.7-1.8$ & 2.8 & $1.3-6.2$ \\
\hline Rapid glues (Loctite®) & 1.8 & $1.1-3.2$ & - & . \\
\hline Paint hardeners (isocyanates) & 2.1 & $1.1-4.2$ & - & \\
\hline Cleaning work & - & . & 1.3 & $0.7-2.1$ \\
\hline
\end{tabular}

$(\mathrm{N}=2)$, painter $(\mathrm{N}=2)$, and various titles $(\mathrm{N}=6)$. The occupational titles for the 39 asthma cases reporting exposure to welding fumes were welder $(\mathrm{N}=7)$, machinery fitter $(\mathrm{N}=6)$, metal worker $(\mathrm{N}=6)$, construction worker $(\mathrm{N}=4)$, electrician $(\mathrm{N}=3)$, farmer $(\mathrm{N}=2)$, plumber $(\mathrm{N}=2)$, truck operator $(\mathrm{N}=2)$ and various titles $(\mathrm{N}=6)$.

\section{Discussion}

The most consistent findings in this study were the increased risks for adult-onset asthma among subjects with occupational exposure to flour dust and among those who occupationally handle resin-based paints. Furthermore, the study indicated an increased asthma risk in association with exposure to welding fumes and textile 
Table 6. Odds ratio (OR) for physician-diagnosed asthma according to occupational exposure. The odds ratios have been determined according to multiple logistic regression models (A-D) adjusted for gender, smoking, and atopy. $(95 \% \mathrm{Cl}=95 \%$ confidence interval)

\begin{tabular}{lll}
\hline Exposure & OR & $95 \% \mathrm{Cl}$ \\
\hline Model A & & \\
$\quad$ Welding fumes & 1.8 & $1.0-3.2$ \\
$\quad$ Soldering & 0.7 & $0.3-1.5$ \\
$\quad$ Grinding & 1.1 & $0.6-2.3$ \\
Model B & & \\
Welding fumes & 1.6 & $0.9-2.9$ \\
Soldering & 0.6 & $0.1-5.7$ \\
Grinding & 1.1 & $0.9-1.4$ \\
Fire fumes & 1.6 & $0.4-6.9$ \\
Rapid glues (Loctite@) & 1.4 & $0.7-2.7$ \\
Model C & & \\
$\quad$ Mineral dust & 1.3 & $0.6-2.7$ \\
Man-made mineral fibers & 0.4 & $0.1-1.1$ \\
Asbestos & 1.8 & $0.9-3.8$ \\
Model D & & \\
$\quad$ Strong acids & 1.2 & $0.4-3.3$ \\
Formaldehyde & 1.0 & \\
Fire fumes & 1.7 & $0.6-4.9$ \\
Engine exhaust & 0.8 & $0.4-1.6$ \\
Rapid glues (Loctite®) & 1.4 & $0.8-2.6$ \\
Paint hardeners (isocyanates) & 2.9 & $1.4-6.1$ \\
Polyurethane foam & 1.4 & $0.5-3.8$ \\
Cutting fluids & 0.8 & $0.3-2.0$ \\
Cleaning work & 1.2 & $0.7-1.9$ \\
Ammonia & 0.9 & $0.5-1.6$ \\
\hline
\end{tabular}

dust, and with the occupational handling of rapid glues (Loctite®), Omnifit@, cyanoacrylates).

We worked with 2 operational definitions of asthma: "physician-diagnosed" asthma and "asthma". The definition of "physician-diagnosed" asthma has been shown to be rather specific but less sensitive; in other words, there is probably a loss of milder cases of asthma (11). To some extent, we have tried to compensate for this lack in the expanded group, the asthma group, which included subjects with asthma-like symptoms that had not been diagnosed as asthma in addition to the subjects in the first category who had already been diagnosed with asthma. The combination of question we used to define asthmalike symptoms was obtained from an Australian study (13). The operational definition of asthma used in our study is probably less specific than the definition of "physician-diagnosed" asthma. This difference is probably the reason for the lower risk estimates for asthma than for "physician-diagnosed" asthma. Even a small decrease in specificity results in lower risk estimates (14).

The exposure assessment was based on the self-reporting of certain types of exposures. The types of exposures we listed were chosen because of a priori hypotheses of an increased risk for asthma. The wording of the questions was as specific as possible, and we avoided general classes of substances such as solvents or dusts. This design probably increased the specificity and decreased the sensitivity of our exposure variables $(9,15)$.
However, a high specificity is preferable when relative risks are calculated in epidemiologic studies.

In order to decrease the misclassification of the exposure assessment, we asked about the time period for the exposures and only considered exposures in our analyses that occurred before the reported onset of disease. We also restricted the analyses to cases of asthma occurring a maximum of 1 year after the exposure ceased.

Several selection biases may exist in this study, the most likely of which is the self-selection process. However, by using a population-based study, we were able to catch workers who leave exposure after developing symptoms. Case-referent studies based on questionnaires are sensitive to "recall bias". In this study a similar fraction of cases and referents returned their questionnaires. However, subjects with asthma may be more prone to report their exposures, especially if the exposure has been discussed in association with asthma.

Atopy was more common among the cases, but, when atopy was stratified for, the association between occupational exposure and asthma did not change. A similar finding has been presented by others (2). Atopy is a risk factor for asthma due to exposure to high-molecularweight agents, such as flour or enzymes. However, most of the exposures examined in this study were indicators for low-molecular-weight agents or irritants, which mostly do not interact with atopy.

Exposure to flour dust was associated with a high risk for asthma, an exposure that is a well-known risk factor for asthma (16). This question was also included as a "positive control". Thus the method has the sensitivity to detect occupational asthma. Occupations in which workers are likely to be exposed to resin-based paints include painting, spray painting, and working with plastic, and a recent study also showed an increased risk for asthma among these occupations (2). The chemical compounds of interest in the paints used by these workers are probably different types of isocyanates, substances that are well-known inducers of occupational asthma (17).

Rapid glues are used in both industry and health care. Most of them are based on acrylates, cyanoacrylates, and methylmetacrylates. Case reports about asthma among workers exposed to cyanoacrylates were first published in the mid-1980s (18-19), followed by a number of similar case reports. However, we are not aware of any epidemiologic study addressing this problem. The results from our study support then the existence of a relation between exposure to cyanoacrylates and adult-onset asthma, although the mechanism is not known.

Exposure to welding fumes implies exposure to respiratory irritants. If stainless steel is welded, exposure to hexavalent chromium is also implied, and, if the steel is painted, exposure to combustion products from burnt paint is also implied. Hence, welders can be exposed to 
a wide variety of irritants and sensitizers. This study shows a relation between exposure to welding fumes and asthma, but we cannot pinpoint the causative exposure. Asthma has been described after welding on stainless steel (20-23), and a slightly increased risk for asthma has been seen in 2 epidemiologic studies (24-25). However, in a review in 1991 the evidence was not regarded as strong enough to support a causal relation between plain steel welding and asthma-onset (26).

An increased risk for asthma among textile workers has been described in previous studies $(1,27)$, but an association is not generally accepted. Exposure to textile dyes has been associated with asthma (28), but textile fabric workers are also probably exposed to dust from crude cotton. Hence some misclassification between asthma and byssinosis may exist.

In conclusion, this population-based case-referent study from Sweden indicates that occupational exposure to acrylate-based compounds and welding fumes is associated with an increased risk for adult-onset asthma.

\section{Acknowledgments}

The study was supported by the Swedish Council for Worklife Research. The authors thank Christina Reuterwall and Ulf Flodin for their valuable assistance with the design of the questionnaire, and Kristina Wass for all her technical assistance.

\section{References}

1. Ng TP, Hong CY, Goh LG, Wong KT, Chung-Koh KT, Ling SL. Risks of asthma associated with occupations in a community-based case-control study. Am J Ind Med 1994;25:70918.

2. Kogevinas M, Antó JM, Soriano JB, Tobias A, Burney P. The risk of asthma attributable to occupational exposures: a population-based study in Spain. Am J Respir Crit Care Med 1996;154:137-43.

3. Fishwick D, Pearce N, D'Souza W, Lewis S, Town I, Armstrong $R$, et al. Occupational asthma in New Zealanders: a population based study. Occup Environ Med 1997;54:3016.

4. Xu X, Christiani DC. Occupational exposures and physiciandiagnosed asthma. Chest 1993;104:1364-70.

5. Flodin U, Ziegler J, Jönsson P, Axelson O. Bronchial asthma and air pollution at workplaces. Scand J Work Environ Health 1996;22:451-6.

6. Mastrangelo G, Bombana S, Priante E, Gallo A, Saia B. Repeated case-control studies as a method of surveillance for asthma in occupations. J Occup Environ Med 1997;39:5157.

7. Blanc P. Occupational asthma in a national disability survey. Chest 1987;92:613-617.

8. Milton DK, Solomon GM, Rosiello RA, Herrick RF. Risk and incidence of asthma attributable to occupational exposure among HMO members. Am J Ind Med 1998;33:1-10.

9. Fritschi L, Siemiatycki J, Richardson L. Self-assessed versus expert-assessed occupational exposures. Am $\mathbf{J}$ Epidemiol 1996; 144:521-7.

10. Torén K, Hermansson B-A. Incidence rate of adult-onset asthma in relation to age, gender, atopy and smoking - a Swedish population based study of 15813 adults. Int J Tuberc Lung Dis 1999;3:192-7.

11. Torén K, Brisman J, Järvholm B. Asthma and asthma-like symptoms in adults assessed by questionnaires. Chest 1993; 104:600-8.

12. Miettinen O. Estimability and estimation in case-referent studies. Am J Epidemiol 1976;103:226-35.

13. Bennet J, Osman J, Blainey AD, Davies RJ. The assessment of a computer administered questionnaire in the differential diagnosis of asthma and chronic airflow limitation. $\mathrm{Br} \mathrm{J}$ Dis Chest 1988;82;249-85.

14. Copeland KT, Checkoway H, McMichael AJ, Holbrook RH. Bias due to misclassification in the estimation of relative risk. Am J Epidemiol 1977; 105:488-95.

15. Teschke K, Kennedy S, Olshan A. Effect of different questionnaire formats on reporting of occupational exposures. Am J Ind Med 1994;26:327—38.

16. Brisman SJ, Järvholm BG. Occurrence of self-reported asthma among Swedish bakers. Scand J Work Environ Health 1995:21:487-93.

17. Chan-Yeung M, Malo J-L. Aetiological agents in occupational asthma. Eur Respir J 1994;7:346-71.

18. Kopp SK, McKay RT, Moller DR, Cassedy K, Brooks SM. Asthma and rhinitis due to ethylcyanoacrylate glue. Ann Int Med 1985;102:613-5.

19. Lozewicz S, Davidson AG, Hopkirk A. Occupational asthma due to methyl methacrylate and cyanoacrylates. Thorax 1985;40:836-9.

20. Keskinen H, Kalliomäki PL, Alanko K. Occupational asthma due to stainless steel welding fumes. Clin Allergy $1980 ; 10: 151-9$.

21. Dahl R, Millelsen HB. Asthma bronkiale og kromallergi udlöst af svejsning af rustfritt stål [in Danish]. Ugeskr Laeger 1982;144:801-2.

22. Björnerem H, Thomassen LM, Wergeland E. Sveiserastma: en kuriositet? eller-? [in Norwegian]. Tidskr Nor Laegeforen 1983;103:1286-88.

23. Moller DR, Brooks SM, Bernstein DI, Cassedy K, Enrione M, Bernstein IL. Delayed anaphylactiod reaction in a worker exposed to chromium. J Allergy Clin Immunol 1986;77:4516.

24. Antti-Poika M, Nordman H, Koskenvuo M, Kaprio J, Jalava M. Role of occupational exposure to airway irritants in the development of asthma. Int Arch Occup Environ Health 1992;64:195-200.

25. Wang ZP, Larsson K, Malmberg P, Sjögren B, Hallberg B-O, Wrangskog K. Asthma, lung function, and bronchial responsiveness in welders. Am J Ind Med 1994;26:741 -54.

26. Sferlazza SJ, Becket WS. The respiratory health of welders. Am Rev Respir Dis 1991;143:1134-48.

27. Hörte LG, Torén K. Smoking adjusted mortality due to asth$\mathrm{ma}$ in a population of Swedish working women. Br J Ind Med 1993;50:575-6.

28. Thorén K, Meding B, Nordlinder R, Belin L. Contact dermatitis and asthma from reactive dyes. Contact Dermatitis $1986 ; 15: 186$.

Received for publication: 21 October 1998

Scand J Work Environ Health 1999, vol 25, no 5 